University of Nebraska - Lincoln

DigitalCommons@University of Nebraska - Lincoln

Faculty Publications from the Harold W. Manter Laboratory of Parasitology

4-2004

Procyrnea Chabaud, 1958 (Nematoda: Habronematoidea: Habronematidae) in Birds from the Area de Conservación Guanacaste, Costa Rica, including Descriptions of 3 New Species

\author{
Luping Zhang \\ University of Toronto \\ Daniel R. Brooks \\ University of Toronto,dnlbrooks@gmail.com \\ Douglas Causey \\ University of Alaska Anchorage, dcausey@uaa.alaska.edu
}

Follow this and additional works at: https://digitalcommons.unl.edu/parasitologyfacpubs

Part of the Parasitology Commons

Zhang, Luping; Brooks, Daniel R.; and Causey, Douglas, "Procyrnea Chabaud, 1958 (Nematoda: Habronematoidea: Habronematidae) in Birds from the Area de Conservación Guanacaste, Costa Rica, including Descriptions of 3 New Species" (2004). Faculty Publications from the Harold W. Manter Laboratory of Parasitology. 230.

https://digitalcommons.unl.edu/parasitologyfacpubs/230

This Article is brought to you for free and open access by the Parasitology, Harold W. Manter Laboratory of at DigitalCommons@University of Nebraska - Lincoln. It has been accepted for inclusion in Faculty Publications from the Harold W. Manter Laboratory of Parasitology by an authorized administrator of DigitalCommons@University of Nebraska - Lincoln. 


\title{
PROCYRNEA CHABAUD, 1958 (NEMATODA: HABRONEMATOIDEA: HABRONEMATIDAE) IN BIRDS FROM THE AREA DE CONSERVACIÓN GUANACASTE, COSTA RICA, INCLUDING DESCRIPTIONS OF 3 NEW SPECIES
}

\author{
Luping Zhang, Daniel R. Brooks ${ }^{\star}$, and Douglas Causey $\dagger$ \\ Centre for Comparative Biology and Biodiversity, Department of Zoology, University of Toronto, Toronto, ON M5S 3G5, Canada. e-mail: \\ dbrooks@zoo.utoronto.ca
}

\begin{abstract}
Four species of Procyrnea were collected in birds from the Area de Conservacion Guanacaste, Costa Rica. Procyrnea brevicaudata n. sp. in Crypturellus cinnamomeus resembles $P$. ficheuri, $P$. murrayi, $P$. ameerae, $P$. dollfusi, and $P$. aptera in lacking lateral alae but differs from all these species in having 2 longitudinal ridges on the left side of the body, in having a sinistral rather than ventral vulvar opening, and in having dorsally bent rather than straight female tails. Procyrnea mawsonae $\mathrm{n}$. sp., in Buteo magnirostris, is similar to P. strialata in body size and in having 2 transverse striated lateral alae, but differs by having longer and differently shaped spicules, and by lacking a single preanal sessile papilla. Procyrnea mclennanae $\mathrm{n}$. sp., in Heliomaster constantii, is similar to P. strialata (Zhang, 1991) and P. mawsonae $\mathrm{n}$. sp. in having 2 transverse striated lateral alae, but it can be distinguished from $P$. strialata and $P$. mawsonae in having 4 rather than 3 small teeth on the interior border of the pseudolabia, in having unequal rather than equal lateral alae, and in having longer spicules. Procyrnea sp., on the basis of a single adult male in Campephilus guatemalensis, resembles $P$. suraiyae, $P$. tulostoma, and $P$. unilateralis in possessing a single and long lateral ala, but can be distinguished from $P$. suraiyae and $P$. tulostoma in the length of the left spicule, in the left spicule having a bifid distal end, the right spicule having a rounded distal end rather than both spicules having pointed distal ends, and in having the lateral ala beginning at the lip region instead of posterior to the cervical papillae. It differs from $P$. uncinipenis in having a spicule ratio of $1: 3.5$ rather than $1: 2.5$, in the left spicule having a bifid rather than alate distal end, and in the absence of a single preanal papilla.
\end{abstract}

Chabaud (1958) proposed Cyrnea to accommodate nematode species assigned traditionally to Habronema, but inhabiting avian hosts and having dorsal and ventral median internal oral processes. He further proposed the subgenus Procyrnea for species of Cyrnea having lateral teeth inserted near the anterior border of the pseudolabia rather than on the posterior part of the pseudolabia, and cervical papillae anterior, rather than posterior, to the nerve ring. Ali (1961) proposed retaining in $\mathrm{Hab}$ ronema all those species placed in Cyrnea by Chabaud (1958), but in the subgenus Aviabronema. However, subsequent authors (e.g., Skrjabin and Sobolev, 1963; Skrjabin et al., 1967; Mawson, 1968; Wang, 1976; Zhang, 1991; Pinto et al., 1996), have accepted Chabaud's (1958) proposal. Chabaud (1975) subsequently raised Procyrnea to generic rank. At present, more than 40 species of Procyrnea have been described.

In this study based on the activities of the inventory of eukaryotic parasites of vertebrates inhabiting the Area de Conservacion Guanacaste (ACG) in northwestern Costa Rica (http: //brooksweb.zoo.utoronto.ca/index.html), we report 4 species of Procyrnea, all of which are apparently undescribed. Paucity of material permits us to name only 3 of these species, but we present information about the fourth as well.

\section{MATERIALS AND METHODS}

Roadside hawks, Buteo magnirostris (Gmelin, 1788) $(\mathrm{n}=9)$, thicket tinamus, Crypturellus cinnamomeus (Lesson, 1842) $(\mathrm{n}=3)$, plaincapped starkthroat, Heliomaster constantii (De Lattre, 1843) $(\mathrm{n}=3)$, and pale-billed woodpecker, Campephilus guatemalensis (Hartlaub, 1844) $(n=4)$, were collected during February 1996, February 2001, and June 2002, and examined for parasites. Nematodes collected from beneath the lining of the gizzard were fixed in glacial acetic acid and preserved and stored in $70 \%$ ethanol. They were later cleared in lactophenol for further examination. Drawings were made with the aid of

Received 7 May 2003; revised 29 September 2003; accepted 29 September 2003.

* To whom correspondence should be addressed.

$\dagger$ Museum of Comparative Zoology, Harvard University, Cambridge, Massachusetts 02138. a drawing tube. Measurements (range, followed by mean in parentheses) are given in micrometers, unless otherwise stated. TBL $=$ total body length.

\section{DESCRIPTIONS}

Procyrnea brevicaudata n. sp.

(Figs. 1-12)

Diagnosis: Body small with distinct transverse striations. Lip region continuous with body contour, lacking constriction. Labial region consisting of 2 pseudolabia and dorsal and ventral labia. Pseudolabia wider at mouth than at base, amphid located on base of pseudolabia, 3 small teeth on interior border of pseudolabia; papillae not observed. Dorsal and ventral labia each consisting of 2 submedian lobes, with 2 papillae on each, and 1 median internal process. Lateral alae absent. Two longitudinal striated ridges present on left lateral side of body, extending from cervical papillae to posterior end of body. Cuticular striations absent between ridges. Buccal capsule laterally compressed. Esophagus clearly divided into short anterior muscular part and long posterior glandular part. Muscular esophagus 5.3$6.5 \%(5.9 \%)$ TBL in male and $4.0-4.6 \%(4.1 \%) \mathrm{TBL}$ in female; glandular esophagus $39.3-51.5 \%(46.3 \%)$ TBL in male and $29.6-33.8 \%(31.2 \%)$ TBL in female. Nerve ring located at the middle of muscular esophagus. Cervical papillae anterior to nerve ring. Excretory pore immediately posterior to nerve ring.

Male $(\mathrm{n}=3)$ : Body length 4.70-5.27 mm (4.97 mm). Maximum width 214-229 (222). Buccal capsule 19-27 (24) long and 10-19 (15) wide. Muscular esophagus 277-304 (293) long and 34-38 (37) wide; glandular esophagus 2.07-2.55 mm (2.30 $\mathrm{mm}$ ) long and 114-129 (120) wide. Nerve ring 209-213 (210) from anterior end; excretory pore 258-285 (270) from anterior end; and cervical papillae 156-163 (158) from anterior end. Posterior end of body curved. Caudal alae well developed and symmetrical, 390-539 (473) long. Caudal alae with longitudinal striations on ventral surface and transverse striations on dorsal surface. Ventral surface of caudal region with prominent longitudinal ridges. Tail with rounded tip, 117-164 (1137) long, 

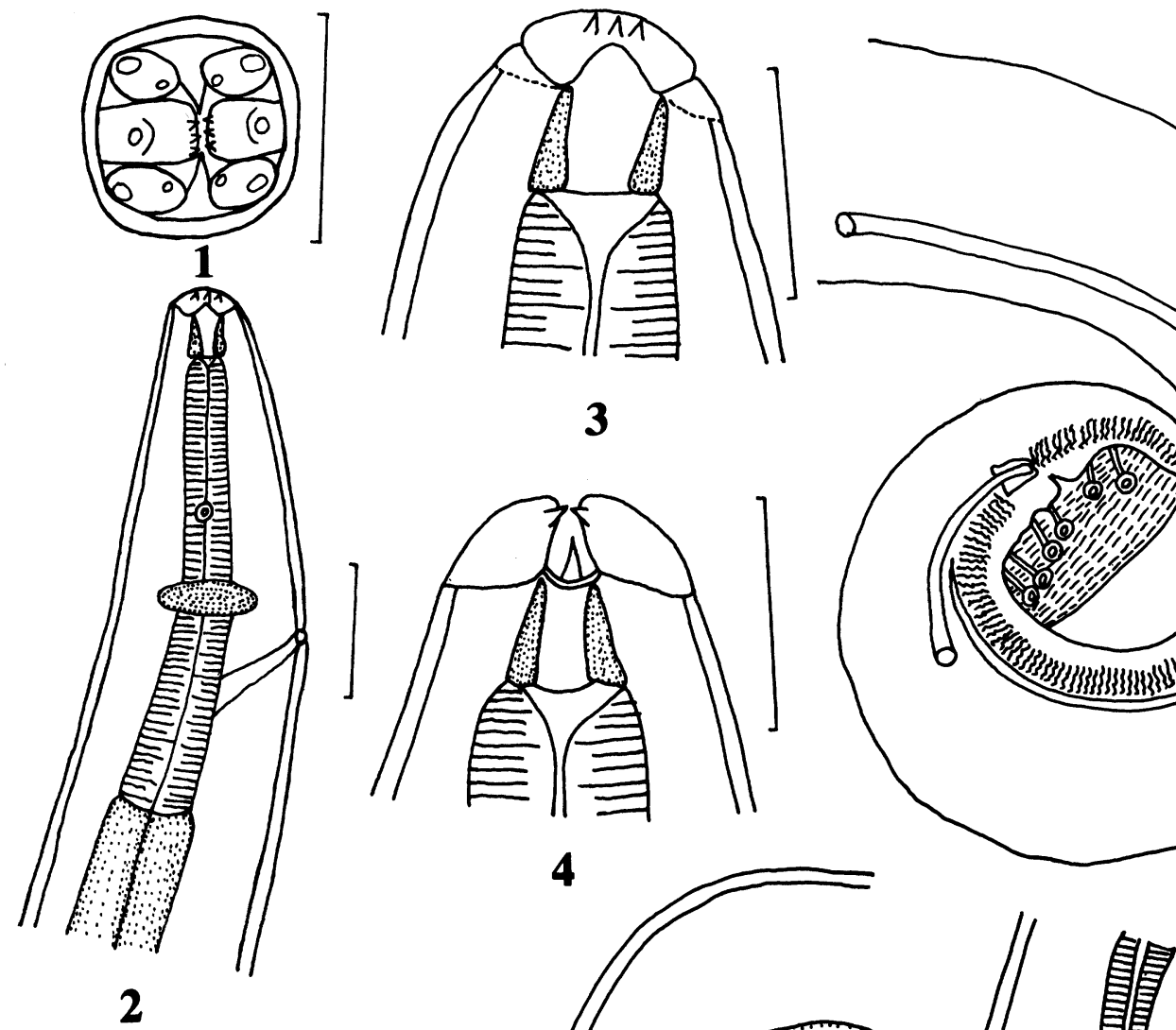
with 4 pairs of symmetrically arranged pedunculate preanal papillae and 2 pairs of symmetrically arranged pedunculate postanal papillae. Ten sessile papillae located near tail tip. Spicules unequal and dissimilar. Left spicule $1.01-1.52 \mathrm{~mm}(1.22 \mathrm{~mm})$ long, with pointed distal end. Right spicule 209-236 (224) long, with rounded tip of distal end. Ratio of right spicule-left spicule, 1:4.8-6.7 (1:5.4). Gubernaculum trowel shaped, dextral side straight, sinistral side slightly bent in the middle (Fig. 7), 38-49 (44) long and 26-37(32) wide.

Female ( $\mathrm{n}=5)$ : Body length 6.80-8.42 mm $(7.86 \mathrm{~mm})$. Maximum width 266-303 (285). Buccal capsule 23-29 (25) long and 11-15 (13) wide. Muscular esophagus 312-346 (323) long and 38-49 (43) wide; glandular esophagus $2.19-2.85 \mathrm{~mm}$ (2.45 mm) long and 118-133 (128) wide. Nerve ring 217-236 (223) from anterior end; excretory pore 266-304 (374) from anterior end; and cervical papillae 171-209 (179) from anterior end. Didelphic. Vulva opening located on left lateral side of body (Figs. 11,12$), 4.10-4.16 \mathrm{~mm}(4.13 \mathrm{~mm})$, or $49.0-52.4 \%$ $(50.4 \%)$ TBL, from anterior end. Tail short and rounded, bent dorsally, 74-111 (88) long. Eggs ellipsoid, thick shelled, embryonated, 40.5-42.3 (42.0) long, 20.2-22.1 (21.0) wide.

\section{Taxonomic summary}

Type host: Crypturellus cinnamomeus (Lesson, 1842) (Aves: Passeriformes: Tinamidae).

Type locality: Camino a Santa Elena, Sector Santa Rosa, ACG, Guanacaste Province, Costa Rica $\left(10^{\circ} 50^{\prime} 44^{\prime \prime} \mathrm{N}\right.$, $\left.85^{\circ} 36^{\prime} 26^{\prime \prime} \mathrm{W}\right)$.

Site of infection: Under the lining of the gizzard.

Prevalence: $33.3 \%$ ( 1 of 3 birds).

Intensity: Three males and 8 females in host.

Type specimens: Holotype, USNPC 94016; allotype, USNPC 94017; paratypes USNPC 94018.

Etymology: The specific epithet refers to the short tail of females.

\section{Remarks}

Procyrnea brevicaudata resembles $P$. ficheuri (Seurat, 1916) Chabaud, 1958, P. murrayi (Ortlepp, 1934) Chabaud, 1958, $P$. ameerae (Ali, 1961) Chabaud, 1975, P. dollfusi (Mawson, 1968) Chabaud, 1975, and P. aptera Wang, 1976, in lacking lateral alae, but differs from all these species by having 2 longitudinal ridges on the left side of the body, in having a sinistral vulvar opening, and in having dorsally bent female tails. The new species also differs from $P$. ficheuri by having a left spicule with a pointed rather than double-barbed tip, a different spicule ratio (1:4.8-6.7 in $P$. brevicaudata vs. 1:4 in $P$. ficheuri), and in lacking a single preanal papilla. Procyrnea brevicaudata can be distinguished from $P$. murrayi and $P$. ameerae by having a longer left spicule (1.01-1.52 mm vs. $0.88-0.89 \mathrm{~mm}$ in $P$. murrayi and $0.78-0.89 \mathrm{~mm}$ in $P$. ameerae), and a different spicule ratio (1:4.8-6.7 in $P$. brevicaudata vs. $1: 3$ in $P$. murrayi and $P$. ameerae). Finally, the new species differs from $P$. dollfusi and $P$. aptera by having a shorter right spicule (209-236 long in $P$. brevicaudata vs. 550 long in $P$. dollfusi and 496 long in $P$. aptera), a different spicule ratio (1:4.8-6.7 in $P$. brevicaudata vs. $1: 2.4-3.2$ in $P$. dollfusi and 1:2.4 in P. aptera), and in having a shorter female tail (74-111 long in $P$. brevicaudata vs. $320-390$ long in $P$. dollfusi and $240-260$ in $P$. aptera).

\section{Procyrnea mawsonae n. sp.}

(Figs. 13-23)

Diagnosis: Body medium size with distinct transverse striations. Lip region continuous with body contour, lacking constriction. Labial region consisting of 2 pseudolabia and dorsal and ventral labia. Pseudolabia wider at mouth than at base, amphid located on base of pseudolabia; 3 small teeth on interior border of pseudolabia; papillae not observed. Dorsal and ventral labia each consisting of 2 submedian lobes, with 2 papillae on each, and a median internal process. Lateral alae well developed, with sinuous striations, extending from lip region to middle of male body and to anterior third of female body, respectively. Buccal capsule laterally compressed. Esophagus clearly divided into short anterior muscular part and long posterior glandular part. Muscular esophagus $3.1-5.9 \%$ (4.2\%) TBL in male and $2.4-3.6 \%(2.9 \%)$ TBL in female; glandular esophagus $19.4-32.2 \%(24.5 \%)$ TBL in male and $14.7-22.3 \%(18.2 \%)$ TBL in female. Nerve ring located at the middle of muscular esophagus. Cervical papillae anterior to nerve ring. Excretory pore immediately posterior to nerve ring.

Male ( $\mathrm{n}=17)$ : Body length 7.21-10.69 mm (9.05 mm). Maximum width 148-222 (191). Lateral alae 3.17-5.35 mm (4.44 mm) long, 39.6-53.8\% (47.6\%) TBL from anterior end. Buccal capsule 15-25 (20) long and 8-15 (11) wide. Muscular esophagus 312-444 (369) long and 25-34 (29) wide; glandular esophagus $1.56-2.43 \mathrm{~mm}(2.18 \mathrm{~mm})$ long and 68-129 (90) wide. Nerve ring 213-266 (246) from anterior end; excretory pore 274-342 (312) from anterior end; and cervical papillae 106-163 (133) from anterior end. Posterior end of body curved. Caudal alae well developed and asymmetrical, left ala relatively long and narrow, 581-903 (700) long; right ala shorter and relatively wider, 460-742 (588) long. Caudal alae with longitudinal striations on ventral surface and transverse striations on dorsal surface. Ventral surface of caudal region with prominent longitudinal ridges. Tail with pointed tip, 175-220 (191) long, with 4 pairs of symmetrically arranged pedunculate preanal papillae and 2 pairs of asymmetrically arranged pedunculate postanal papillae. Ten sessile papillae located near tail tip. Spicules unequal and dissimilar. Left spicule 665-874 (754) long, distal end divided into 2 branches connected by transparent membrane. Right spicule 247-323 (291) long, tip of distal end bent proximally, forming hooklike structure. Ratio of right spiculeleft spicule, 1:2.2-2.9 (1:2.6). Gubernaculum trowel shaped, with small lateral projection at proximal end of dextral side, straight sinistral side (Fig. 22), 38-61 (47) long and 16-23 (20) wide.

Female ( $\mathrm{n}=13)$ : Body length 11.42-16.04 mm (13.94 mm). Maximum width 222-326 (275). Lateral alae 4.07-6.59 mm (5.00 mm) long, 27.6-45.2\% (34.1\%) TBL from anterior end. Buccal capsule 18-23 (21) long and 13-19 (15) wide. Muscular esophagus 342-456 (406) long and 30-38 (34) wide; glandular esophagus $2.24-2.89 \mathrm{~mm}(2.50 \mathrm{~mm})$ long and 68-141 (103) wide. Nerve ring 217-285 (267) from anterior end; excretory pore 270-395 (347) from anterior end; and cervical papillae 114-175 (140) from anterior end. Didelphic. Vulva 5.27-7.21 $\mathrm{mm}(6.60 \mathrm{~mm})$ or $43.2-52.3 \%(47.6 \%)$ TBL from anterior end. Tail 182-266 (226) long, pointed. Eggs ellipsoid, thick shelled, embryonated, 31.3-38.6 (35.1) long, 16.6-22.1 (19.0) wide. 


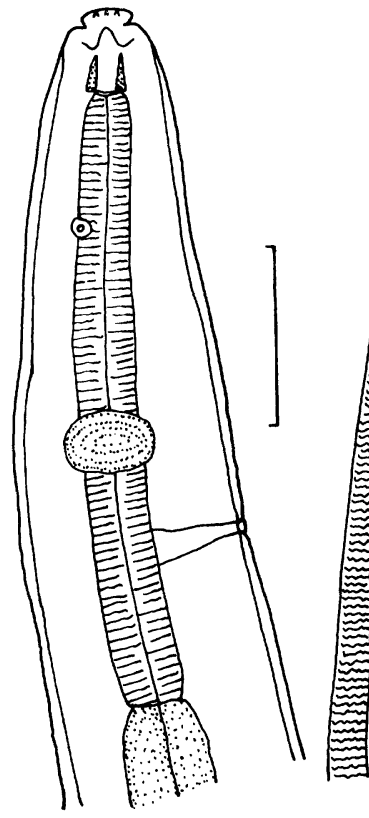

13

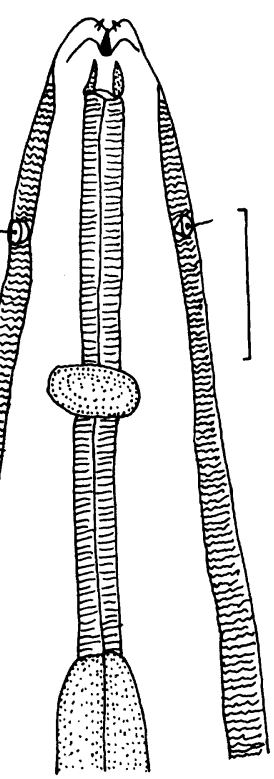

14

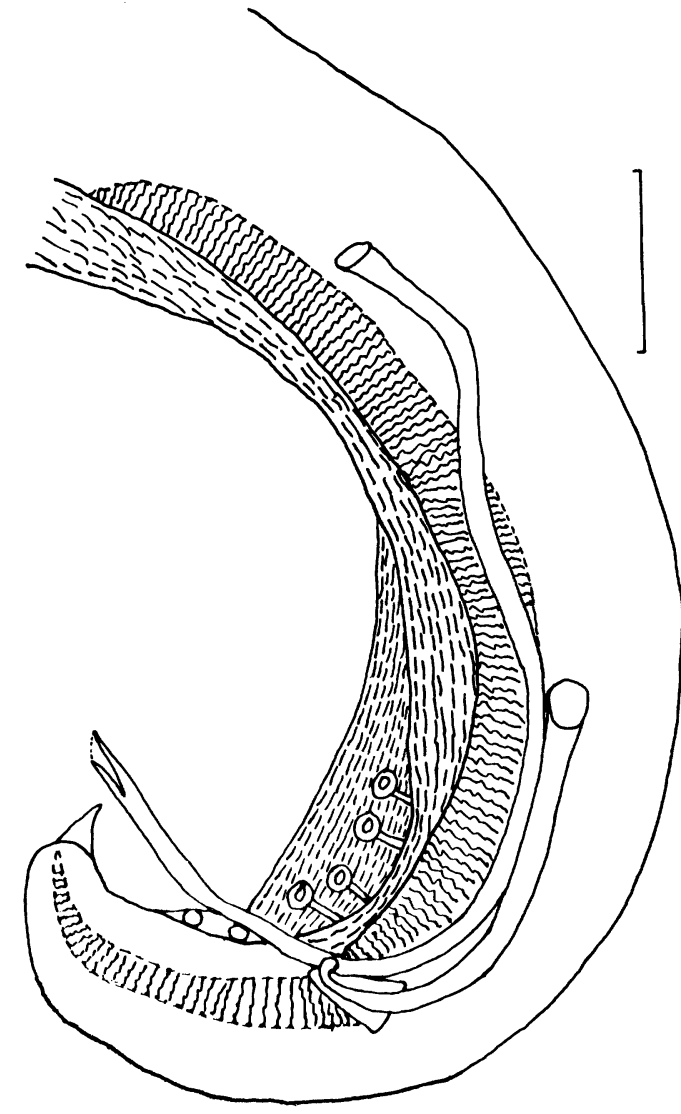

18

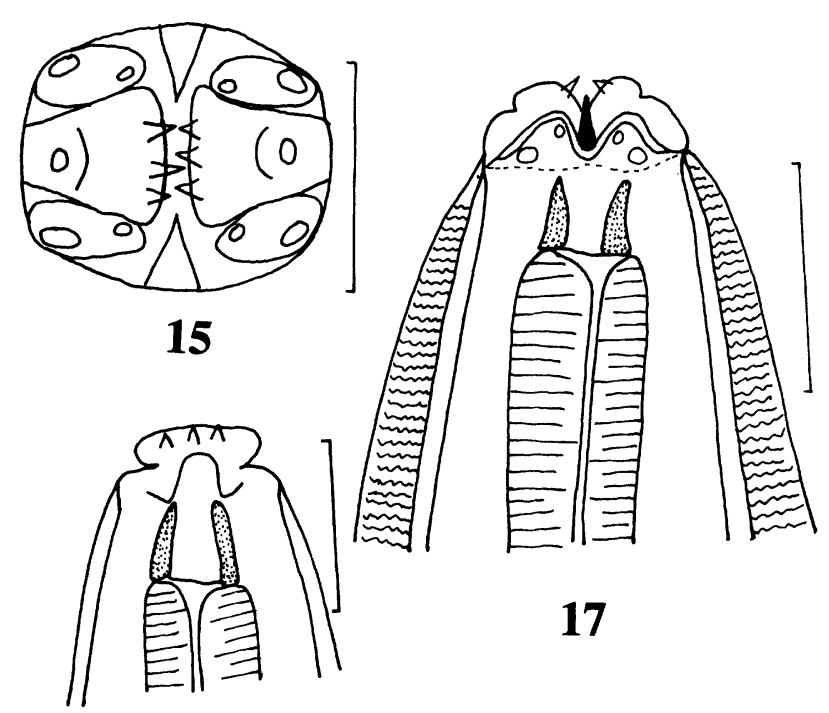

16

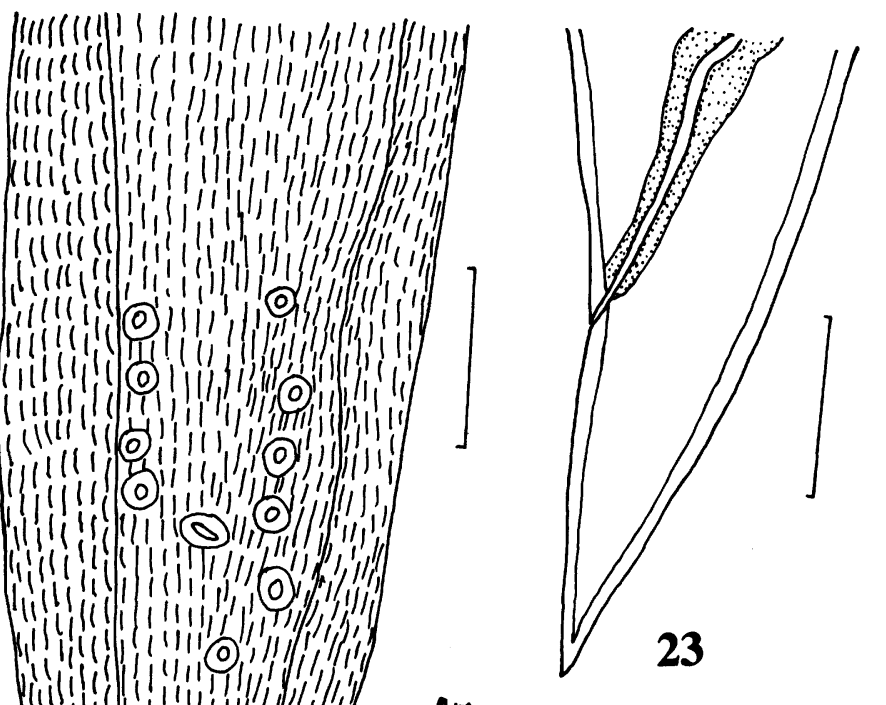

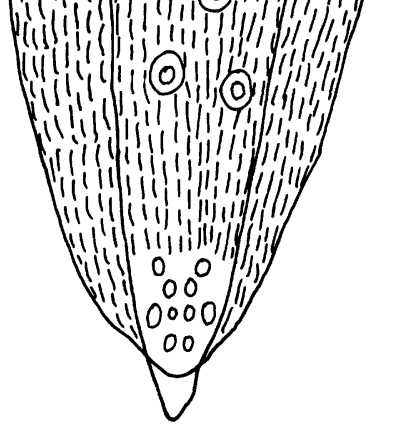

19
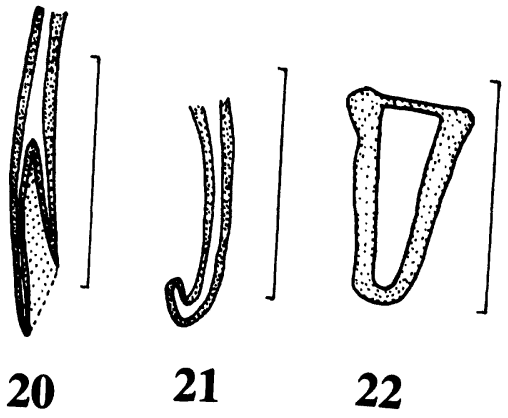

Figures 13-23. Procyrnea mawsonae n. sp. 13. Anterior end of female, lateral view. 14. Anterior end of female, ventral view. 15. Anterior extremity, en face view. 16. Anterior extremity of female, lateral view. 17. Anterior extremity of female, ventral view. 18. Posterior end of male, lateral view. 19. Posterior end of male, ventral view. 20. Distal end of left spicule. 21. Distal end of right spicule. 22. Gubernaculum. 23. Posterior end of female, lateral view. Bar $=100 \mu \mathrm{m}$ (Figures 13, 14, 18, 19, 23); Bar $=50 \mu \mathrm{m}($ Figures 15, 16, 17, 20, 21, 22). 


\section{Taxonomic summary}

Type host: Buteo magnirostris (Gmelin, 1788) (Aves: Falconiformes: Accipitridae).

Type locality: Camino de las Mesas, Sector Santa Rosa, ACG, Guanacaste Province, Costa Rica, 10 $50^{\prime} 44^{\prime \prime} \mathrm{N}$ $85^{\circ} 36^{\prime} 26^{\prime \prime} \mathrm{W}$.

Other locality: Cafetal, Sector Santa Rosa, ACG, Guanacaste Province, Costa Rica $\left(10^{\circ} 52^{\prime} 53^{\prime \prime} \mathrm{N}, 85^{\circ} 36^{\prime} 42^{\prime \prime} \mathrm{W}\right)$.

Site of infection: Under the lining of the gizzard.

Prevalence: $33 \%$ (3 of 9 birds).

Intensity: Six to 15 .

Type specimens: Holotype, USNPC 94010; allotype, USNPC 94011; paratype, USNPC 94012.

Etymology: The new species is named for Professor Patricia M. Mawson, in recognition of her contributions to our knowledge of the nematode parasites of birds.

\section{Remarks}

Procyrnea mawsonae most closely resembles $P$. strialata Zhang, 1991, the only other member of the genus presently known to have 2 transverse striated lateral alae (Zhang, 1991). The new species is similar in body size to $P$. strialata, but differs by having longer spicules (left spicule 665-874 long, right spicule 247-323 long in P. mawsonae vs. left spicule 517563 long, right spicule 184-220 long in $P$. strialata). In addition, the distal end of the left spicule is divided into 2 branches and the distal end of the right spicule is hooklike in $P$. mawsonae, whereas both spicules have pointed distal ends in $P$. strialata. Finally, $P$. strialata males possess a single preanal sessile papilla, which $P$. mawsonae males lack.

\section{Procyrnea mclennanae n. sp.}

(Figs. 23-33)

Diagnosis: Body medium size with distinct transverse striations. Lip region continuous with body contour, lacking constriction. Labial region consisting of 2 pseudolabia and dorsal and ventral labia. Pseudolabia strongly cuticularized at mouth and weakly cuticularized at base, amphid located on base of pseudolabia; 4 small teeth on interior border of pseudolabia; papillae not observed. Dorsal and ventral labia each consisting of 2 submedian lobes, with 2 papillae on each, and a median internal process. Lateral alae are present, with sinuous striations, extending from lip region to middle of male body, and to anterior third of female body, respectively. Right lateral ala wider than left one. Buccal capsule laterally compressed. Esophagus clearly divided into short anterior muscular part and long posterior glandular part. Muscular esophagus 3.1-3.8\% (3.4\%) TBL in male and $1.7-2.4 \%(2.1 \%)$ TBL in female; glandular esophagus $15.1-16.8 \%(16.1 \%)$ TBL in male and 9.4$10.6 \%(9.9 \%) \mathrm{TBL}$ in female. Nerve ring located at posterior part of muscular esophagus. Cervical papillae anterior to nerve ring. Excretory pore posterior to nerve ring.

Male $(\mathrm{n}=3)$ : Body length 10.24-12.42 mm (11.53 mm). Maximum width 323-368 (350). Lateral alae 5.16-6.45 mm (5.86 mm) long, 50-52\% (50.8\%) TBL from anterior end. Right lateral ala 18-24 (22) wide and left lateral ala 6-10 (8) wide. Buccal capsule 32-38 (34) long and 14-16 (15) wide. Muscular esophagus 381-393 (387) long and 38-44 (42) wide; glandular esophagus $1.68-2.00 \mathrm{~mm}(1.85 \mathrm{~mm})$ long and 101-139 (126) wide. Nerve ring 290-323 (312) from anterior end; excretory pore 387-432 (402) from anterior end; and cervical papillae 168-190 (175) from anterior end. Posterior end of body curved. Caudal alae well developed and symmetrical, 1064-1097 (1082) long. Caudal alae with longitudinal striations on ventral surface and transverse striations on dorsal surface. Ventral surface of caudal region with prominent longitudinal ridges. Tail with rounded tip, 387-419 (403) long, with 4 pairs of symmetrically arranged pedunculate preanal papillae and 2 pairs of asymmetrically arranged pedunculate postanal papillae. Ten sessile papillae located near tail tip. Spicules unequal and dissimilar. Left spicule $1.52-1.66 \mathrm{~mm}(1.58 \mathrm{~mm})$ long, with bifurcate distal end. Right spicule 460-539 (502) long, distal end with hooklike structure. Ratio of right spicule-left spicule, 1: $2.8-3.4$ (1:3.2). Gubernaculum trowel shaped, with lateral projection from proximal end of sinistral side (Fig. 32), 29-37 (33) long and 31-32 (31) wide.

Female $(\mathrm{n}=4)$ : Body length $21.61-23.39 \mathrm{~mm}(22.70 \mathrm{~mm})$. Maximum width 439-458 (448). Lateral alae 7.18-8.63 mm (7.58 mm) long, 30.9-39.9\% (33.5\%) TBL from anterior end. Right lateral ala 23-29 (25) wide and left one 8-10 (9) wide. Buccal capsule 32-38 (36) long and 13-19 (16) wide. Muscular esophagus 400-548 (479) long and 48-63 (56) wide; glandular esophagus $2.16-2.32 \mathrm{~mm}(2.24 \mathrm{~mm})$ long and 152-159 (155) wide. Nerve ring 335-393 (356) from anterior end; excretory pore 419-529 (474) from anterior end; and cervical papillae 171-212 (193) from anterior end. Didelphic. Vulva located behind middle of body, $12.58-15.32 \mathrm{~mm}(13.76 \mathrm{~mm})$ from anterior end. Tail rounded, 297-355 (321) long, tip of tail with a small rounded protuberance. Eggs ellipsoid, thick shelled, embryonated, 33.8-38.6 (36.2) long, 19.3-20.9 (20.4) wide.

\section{Taxonomic summary}

Type host: Heliomaster constantii (De Lattre, 1843) (Aves: Apodiformes: Trochilidae).

Type locality: Bosque San Emilio, Sector Santa Rosa, ACG, Guanacaste Province, Costa Rica, $10^{\circ} 51^{\prime} 13^{\prime \prime} \mathrm{N}, 85^{\circ} 36^{\prime} 32^{\prime \prime} \mathrm{W}$.

Other locality: Cafetal, Sector Santa Rosa, ACG, Guanacaste Province, Costa Rica ( $\left.10^{\circ} 51^{\prime} 35^{\prime \prime} \mathrm{N}, 85^{\circ} 36^{\prime} 37^{\prime \prime} \mathrm{W}\right)$.

Site of infection: Under the lining of the gizzard.

Prevalence: Sixty-seven percent (2 of 3 birds).

Intensity: Two to 5 .

Type specimens: Holotype, USNPC 94013; allotype, USNPC 94014; paratype, USNPC 94015.

Etymology: The new species is named for Professor Deborah A. McLennan, Department of Zoology, University of Toronto, Canada.

\section{Remarks}

Procyrnea mclennanae is similar to $P$. strialata Zhang, 1991 and $P$. mawsonae $\mathrm{n}$. sp. in having 2 transverse striated lateral alae, but it can be distinguished from $P$. strialata and $P$. mawsonae in having 4 rather than 3 small teeth on the interior border of the pseudolabia, in having unequal rather than equal lateral alae, and in having longer spicules (left spicule 1.52-1.66 mm long, right spicule 460-539 long in P. mclennanae vs. left spicule 517-563 long, right spicule 184-220 long in P. striala$\mathrm{ta}$, and left spicule 665-874 long, right spicule 247-323 long 


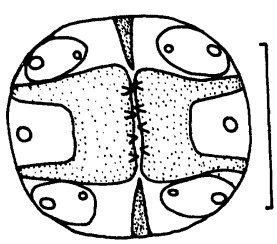

24

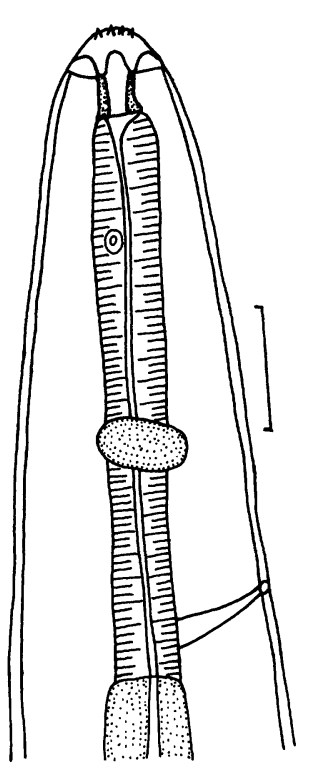

25

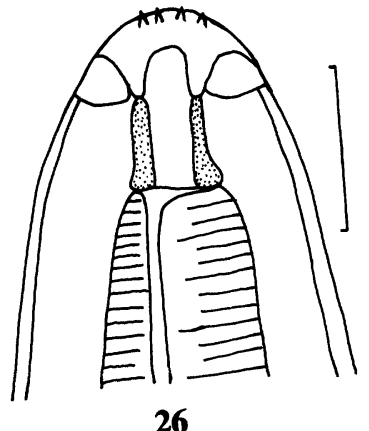

26

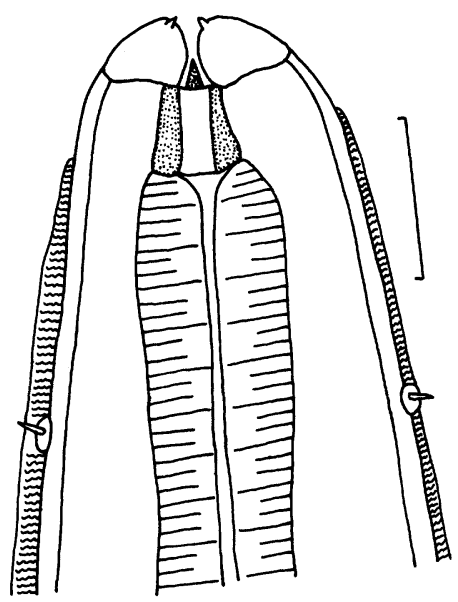

27

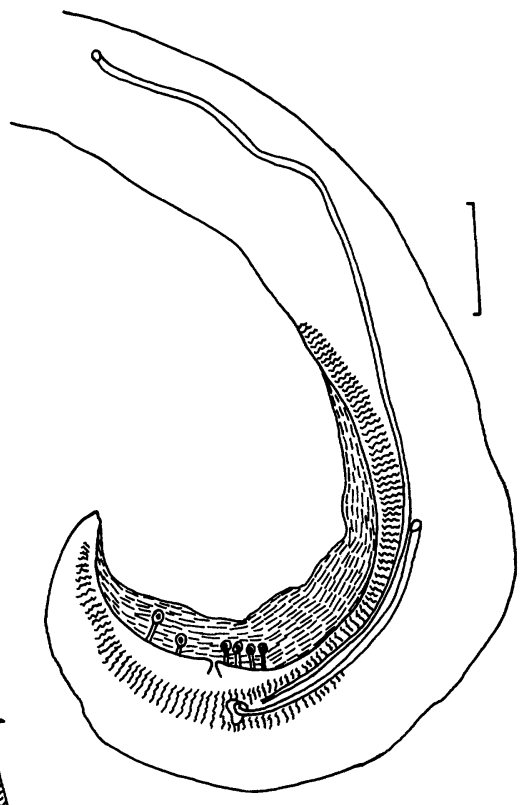

28

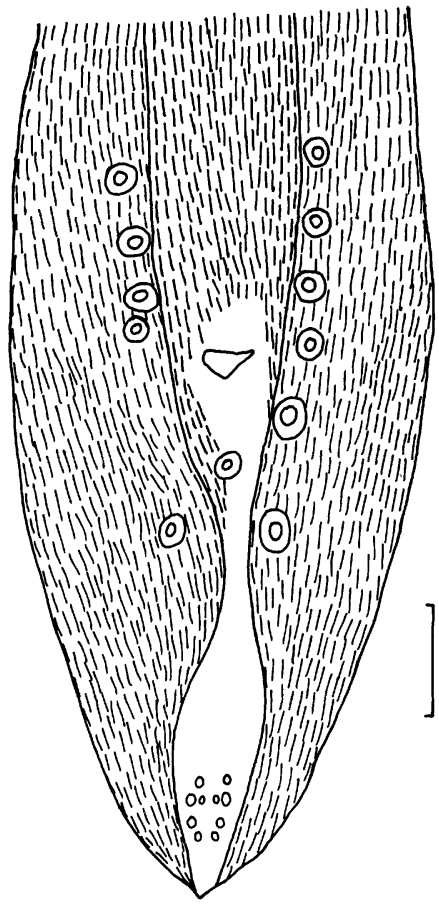

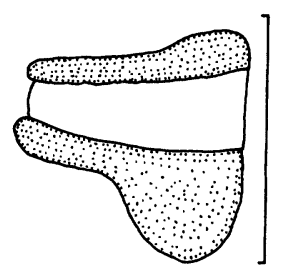

32

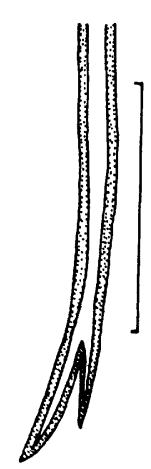

30
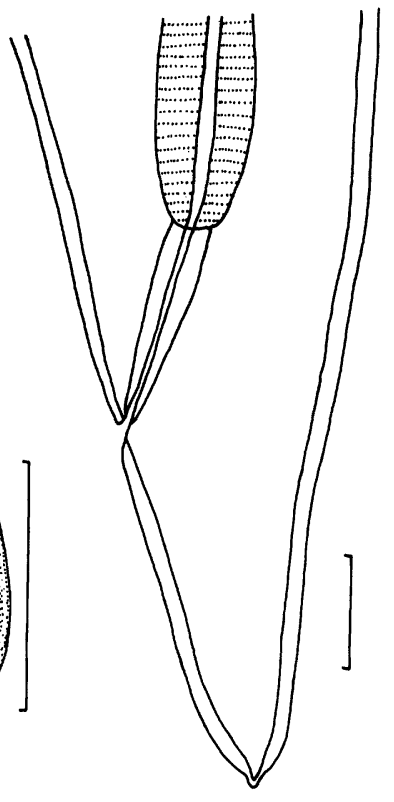

33

29

Figures 23-33. Procyrnea mclennanae n. sp. 24. Anterior extremity, en face view. 25. Anterior end of female, lateral view. 26. Anterior extremity of female, lateral view. 27. Anterior extremity of female, ventral view. 28. Posterior end of male, lateral view. 29. Posterior end of male, ventral view. 30. Distal end of left spicule. 31. Distal end of right spicule. 32. Gubernaculum. 33. Posterior end of female, lateral view. $\mathrm{Bar}=50 \mu \mathrm{m}$ (Figures 24, 26, 27, 29, 30, 31, 32); Bar = $100 \mu \mathrm{m}$ (Figures 25, 33); Bar $=200 \mu \mathrm{m}$ (Figure 28). 
in $P$. mawsonae). In addition, the distal end of the left spicule is divided into 2 branches, and the distal end of the right spicule is hooklike in $P$. mclennanae, whereas both spicules have pointed distal ends in $P$. strialata. Also, $P$. strialata males possess a single preanal sessile papilla, which $P$. mclennanae males lack. Finally, $P$. mclennanae has a rounded female tail, whereas $P$. mawsonae has a pointed female tail.

\section{Procyrnea sp.}

(Figs. 34-42)

Diagnosis: Body medium size with distinct transverse striations. Lip region continuous with body contour, lacking constriction. Labial region consisting of 2 pseudolabia and dorsal and ventral labia. Pseudolabia wider at mouth than at base, amphid located on base of pseudolabia; 3 small teeth on interior border of pseudolabia, papillae not observed. Dorsal and ventral labia each consisting of 2 submedian lobes, with 2 papillae on each, and a median internal process. Lateral ala on right side of body lacking sinuous striations, originating posterior to lips, extending posteriorly to middle of male body. Buccal capsule laterally compressed. Esophagus clearly divided into short anterior muscular part and long posterior glandular part. Muscular esophagus $4.4 \%$ TBL in male; glandular esophagus $22.2 \% \mathrm{TBL}$ in male. Nerve ring located at the middle of muscular esophagus. Cervical papillae anterior to nerve ring. Excretory pore immediately posterior to nerve ring.

Male $(\mathrm{n}=1)$ : Body length $10.69 \mathrm{~mm}$. Maximum width 326 . Lateral ala $6.19 \mathrm{~mm}$ long, 58\% TBL from anterior end. Buccal capsule 30 long and 27 wide. Muscular esophagus 475 long and 42 wide; glandular esophagus $2.38 \mathrm{~mm}$ long and 187 wide. Nerve ring 292 from anterior end; excretory pore 406 from anterior end; cervical papillae 182 from anterior end. Posterior end of body curved. Caudal alae well developed and symmetrical, 774 long. Caudal alae with longitudinal striations on ventral surface and transverse striations on dorsal surface. Ventral surface of caudal region with prominent longitudinal ridges. Tail 271 long, with pointed tip, with 4 pairs of pedunculate preanal papillae arranged symmetrically and 2 pairs of pedunculate postanal papillae arranged asymmetrically. Twelve sessile papillae located near the tail tip. Spicules unequal and dissimilar. Left spicule $1.43 \mathrm{~mm}$ long with bifid distal end. Right spicule 410 long, with rounded distal end. Ratio of right spicule-left spicule 1:3.5. Gubernaculum trowel shaped, with digitiform projection extending distally from sinistral side (Fig. 42), 49 long and 42 wide.

\section{Taxonomic summary}

Host: Campephilus guatemalensis (Hartlaub, 1844) (Aves: Piciformes: Picidae).

Locality: Estacion Maritza, Sector Maritza, ACG, Guanacaste Province, Costa Rica $\left(32^{\circ} 65^{\prime} 55^{\prime \prime} \mathrm{N}, 37^{\circ} 27^{\prime} 68^{\prime \prime} \mathrm{W}\right)$.

Site of infection: Under the lining of the gizzard.

Prevalence: Twenty five percent ( 1 of 4 birds).

Intensity: One male in 1 host.

Voucher specimen: USNPC 94019.

\section{Remarks}

We are convinced this specimen represents an undescribed species but refrain from naming it at this time because of the paucity of material. The single male resembles $P$. suraiyae (Ali, 1961) Chabaud, 1975, P. tulostoma (Hemprich and Ehrenberg, 1866) Chabaud, 1958 and P. unilateralis (Molin, 1860) Chabaud, 1958 in possessing a single and long lateral ala, but can be distinguished from $P$. suraiyae and $P$. tulostoma in the length of the left spicule (1.43 mm long in Procyrnea sp. vs. $0.93-1.12 \mathrm{~mm}$ in $P$. suraiyae and $1.9 \mathrm{~mm}$ in $P$. tulostoma), in having complex spicule morphology (left spicule with bifid distal end and right spicule with rounded distal end) rather than spicules with simple pointed distal ends, and in having lateral alae extending from the lip region rather than from immediately posterior to the cervical papillae. The new species differs from $P$. uncinipenis in having a spicule ratio of $1: 3.5$ rather than 1 : 2.5 , in having the left spicule with a bifid rather than alate distal end, and in lacking a single preanal papilla.

\section{DISCUSSION}

Each species of Procyrnea reported in this study was collected in a single host species, each of which is similar in having well-defined territories, visiting feeding areas on a continual daily basis. However, beyond that, the 4 host species represent a diverse sample of tropical dry forest birds, habitats, and feeding ecologies. The roadside hawk ( $B$. magnirostris), so called because of its habit of perching high in trees near open fields and roads, is a small $(38 \mathrm{~cm}, 290 \mathrm{~g})$ predator of large insects, reptiles, and small mammals. It is rarely found in deep or humid parts of the forest, preferring more xeric and open habitats. In contrast, the thicket tinamu (C. cinnamomeus) is rarely seen away from the dense understory of old-growth and secondary forest, and is an omnivore of many different foods picked up from the ground and low vegetation. Tinamus can be found throughout the tropical dry forest but are most commonly encountered around water-dominated terrestrial habitats, such as riparian edges and emergent shrubbery. The pale-billed woodpecker ( $C$. guatemalensis), like all climbing woodpeckers, is found mostly in the upper canopy of old-growth and mature secondary growth forests, feeding on boring beetles and their larvae. The plain-capped starkthroat, $H$. constantii, like all hummingbirds, is generally assumed to be a florivore and nectarivore. Whereas this is likely to be true during the time of year when flowers are present, some specimens of $H$. constantii infected with $P$. mclennanae were collected in the dry forest during the dry season, when there are no flowers available. During such periods, hummingbirds likely sustain themselves on a diet of insects. We previously reported a prosthogonomid digenean, Whallwachsia illuminata Zamparo et al., 2003, in another hummingbird of the tropical dry forest region of the ACG (Zamaro et al., 2003). Known prosthogonomid life cycles involve insect second intermediate hosts, and we suspect $P$. mclennanae is also transmitted by insect intermediate hosts.

\section{ACKNOWLEDGMENTS}

We are grateful to the scientific and technical staff of the ACG for support of this study, in particular: Elda Araya, Roger Blanco, Carolina Cano, Maria Marta Chavarría, Felipe Chavarría, Roberto Espinoza, Dunia Garcia, Guillermo Jimenez, Elba Lopez, Sigifredo Marin, Alejandro Masis, Calixto Moraga, Fredy Quesada, and Petrona Rios. We also thank Dan Janzen and Winnie Hallwachs, scientific advisers to the ACG, for their support. Host specimens were collected by D.C., Jeremiah Trimble (MCZ), and Calixto Moraga (ACG) under the authority 


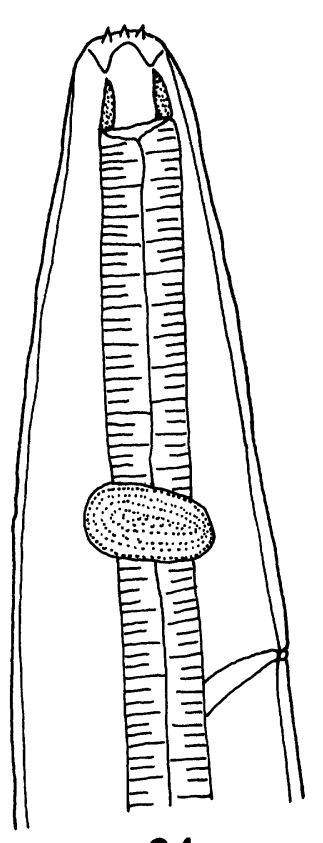

34

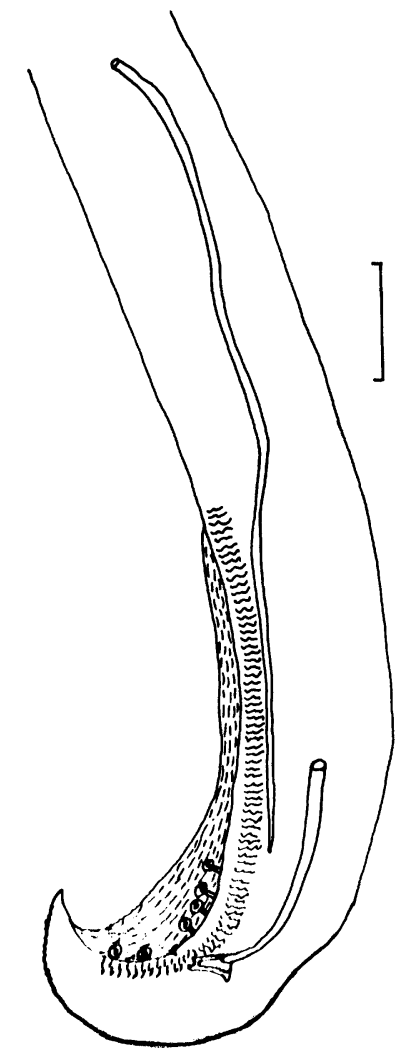

38

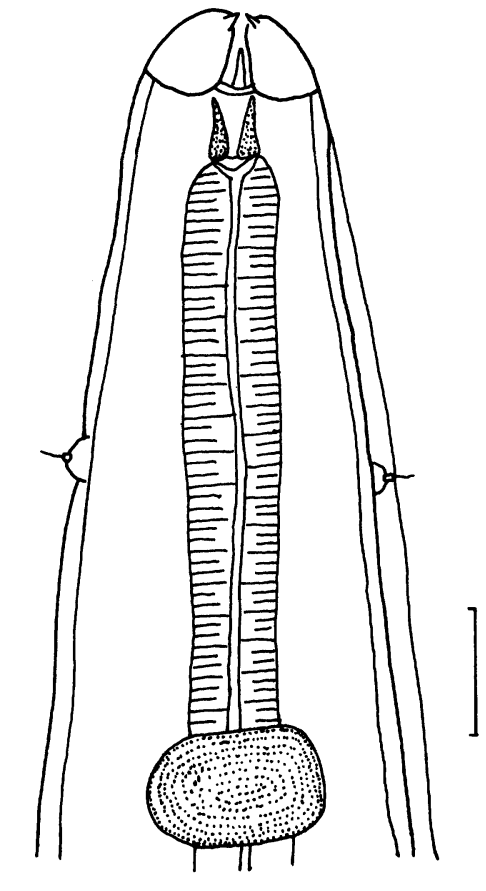

35

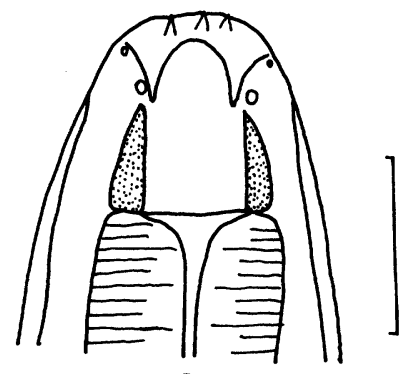

36

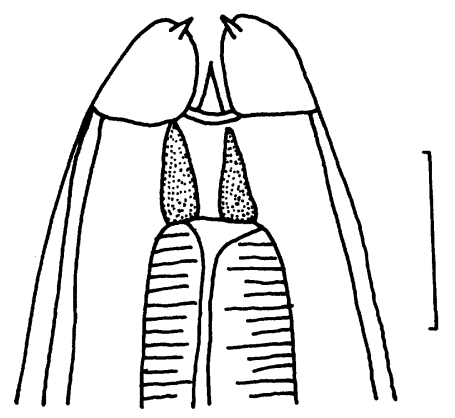

37
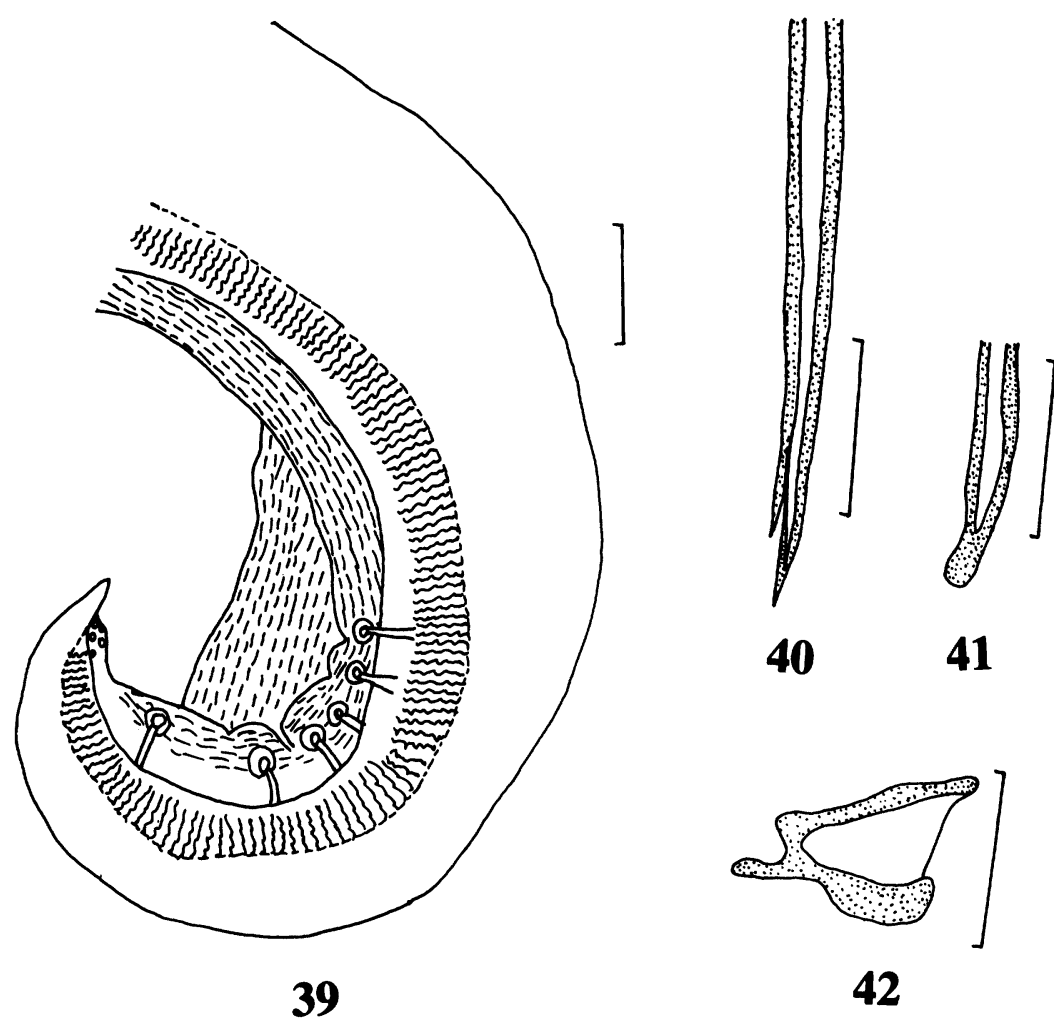

Figures 34-42. Procyrnea sp. 34. Anterior region of female, lateral view. 35. Anterior end of female, dorsal view. 36. Anterior extremity of female, lateral view. 37. Anterior extremity of female, ventral view. 38, 39. Posterior end of male, lateral view. 40. Distal end of left spicule. 41. Distal end of right spicule. 42. Gubernaculum. Bars $=100 \mu \mathrm{m}$ (Figures 34, 39); Bar $=50 \mu \mathrm{m}$ (Figures 35, 36, 37, 40, 41, 42); Bar $=200 \mu \mathrm{m}$ (Figure 38). 
of CITES Permit \#US9258251, CITES Permit \#CR9123440, Costa Rica Ministero del Ambiente y Energia Licencia \#203640283 and Resoluciones \#215-2001-OFAU and \#411-2001-OFAU, Harvard University IACUC Protocol 21-09, and USDA APHIS Permit \#47956 (Form VS16-6A). Host necropsy and parasite collections were made by D.R.B., D.C., Elda Araya, Sara Brant, Marie Causey, Ben Hanelt, Calixto Moraga, and Petrona Rios. This study was funded by a research grant from the Natural Sciences and Engineering Research Council (NSERC) of Canada to D.R.B. and by a grant from the MCZ Putnam Expedition Fund to D.C.

\section{LITERATURE CITED}

ALI, S. M. 1961. On some new nematodes (Habronematinae) from birds in Hyderabad, India, and the relationships of the genus Habronema. Journal of Helminthology 35: 1-48.

Chabaud, A. G. 1958. Essai de classification des nematodes Habronematinae. Annales de Parasitologie Humaine et Comparee 33: 445508.

- 1975. Keys to the genera of the order Spirurida. Part 2. Spiruroidea, Habronematoidea and Acuarioidea. In CIH Keys to the nematode parasites of vertebrates, No. 3, R. C. Anderson, A. G. Chabaud, and S. Willmott (eds.). Commonwealth Agricultural Bureaux, Farnham Royal, U.K., p. 29-58.

Mawson, P. M. 1968. Habronematinae (nematoda: Spiruridae) from Australian birds. Parasitology 58: 745-767.
PinTo, R. M., J. J. ViCENTE, AND D. NoRONHA. 1996. Nematode parasites of Brazilian Piciformes birds: a general survey with description of Procyrnea anterovulvata n. sp. (Habronematoidea: Habronematidae). Memorias do Instituto Oswaldo Cruz 91: 479-487.

SkrJabin, K. I., AND A. A. Sobolev. 1963. Principles of Nematology 11. Spirurata of animals and man and the diseases caused by them. Part 1. Spiruroidea. Izdatel'stvo Nauka, Moscow, Russia, 333 p. [In Russian.]

VASHKIN. 1967. Principles of Nematology 19. Spirurata of animals and man and the diseases caused by them. Part 5. Supplement. Izdatel'stvo Nauka, Moscow, Russia, 240 p. [In Russian.]

WANG, P. 1976. Notes on some new nematodes of suborder Spirurata from Fujian, China. Acta Zoologica Sinica 22: 393-402. [In Chinese.]

ZAMPARO, D., D. R. BRoOKS, AND D. CAUSEY. 2003. Whallwachsia illuminata n. g., n. sp. (Trematoda: Digenea: Plagiorchiformes: Prosthogonimidae) in the Steely-vented hummingbird Amazilia saucerrottei (Aves: Apodiformes: Trochilidae) and the Yellow-olive flycatcher Tolmomyias sulphurescens (Aves: Passeriformes: Tyrannidae) from the Area de Conservación Guanacaste, Guanacaste, Costa Rica. Journal of Parasitology 89: 814-818.

ZHANG, L. P. 1991. Description of a new species of spirurid nematodes (Spirurida: Spiruridae). Acta Zootaxonomica Sinica 16: 138-142. [In Chinese.] 